INRA Prod. Anim.,

2013, 26 (2), 193-206

\title{
La traite, un outil de pilotage du troupeau et de maîtrise de la qualité du lait en élevage bovin laitier
}

\author{
J. GUINARD-FLAMENT ${ }^{1,2,3}$, P.-G. MARNET $T^{1,2,3}$, I. VERDIER-METZ ${ }^{4}$, C. HURTAUD ${ }^{1,2}$, \\ M.-C. MONTEL ${ }^{4}$, K. STELWAGEN ${ }^{5}$, D. POMIĖ $S^{6,7}$ \\ ${ }^{1}$ Agrocampus Ouest, UMR1348 PEGASE, F-35000 Rennes, France \\ 2 INRA, UMR1348 PEGASE, F-35590 Saint-Gilles, France \\ ${ }^{3}$ Université Européenne de Bretagne, F-35000 Rennes, France \\ ${ }^{4}$ INRA, UR0545 LRF, F-15000 Aurillac, France \\ ${ }^{5}$ SciLactis Ltd, Waikato Innovation Park, Ruakura Rd, Hamilton 3240, New Zealand \\ ${ }^{6}$ INRA, UMR1213 Herbivores, F-63122 Saint-Genès-Champanelle, France \\ ${ }^{7}$ Clermont Université, VetAgro Sup, UMR1213 Herbivores, BP 10448, F-63000, Clermont-Ferrand, France \\ Courriel : Jocelyne.Flament@agrocampus-ouest.fr
}

Les techniques alternatives mises en œuvre pour la traite des vaches laitières sont surtout développées pour contribuer à la gestion du travail sur l'exploitation. Mais elles n'ont pas ce seul intérêt. Elles permettent aussi de maîtriser la qualité du lait, d'ajuster le niveau de production laitière, et de gérer la carrière et la santé des animaux.

Dans les élevages bovins laitiers, la traite mécanique est une opération routinière qui vise à maximiser la quantité de lait produit chaque jour, à un coût économiquement et socialement acceptable. Actuellement, les animaux sont généralement traits 2 fois par jour durant toute la lactation, avec un intervalle maximum de $16 \mathrm{~h}$ entre traites. Néanmoins, malgré son caractère répétitif, la traite reste une étape sensible, dont la perturbation peut avoir des répercussions négatives sur les qualités hygiénique, sanitaire, nutritionnelle, sensorielle et technologique du lait et sur la santé de l'animal. Ainsi, la traite doit être rapide, complète et non agressive pour bénéficier des effets du réflexe d'éjection du lait sur le volume de lait collecté, et éviter l'écrémage partiel du lait.

De fait, les pratiques et conditions matérielles dans lesquelles se déroule la traite sont relativement standardisées (voire normalisées) pour permettre l'expression du potentiel laitier des animaux tout en limitant ses impacts négatifs. L'éleveur dispose cependant de libertés d'action via le choix et les réglages du matériel de traite et du stockage du lait (manchons, faisceaux trayeurs, niveau de vide et de pulsation, modes de refroidissement), la réalisation de la traite ellemême (préparation de la mamelle, hygiène de traite) et la modulation des fréquences/intervalles de traite. Ainsi, la traite au sens large est un levier que l'éleveur peut utiliser pour répondre à ses attentes, au même titre que l'alimentation et la sélection des animaux.
Aujourd'hui, les modifications portant sur les pratiques de traite sont surtout considérées comme un outil de gestion du travail dans les exploitations laitières bovines (Pomiès et al 2008, Agabriel et al 2012), où la traite représente $50 \%$ du travail d'astreinte (Chauvat et al 2003). Les autres motivations des éleveurs, rarement compilées à ce jour, relèvent d'objectifs technicoéconomiques. Les éleveurs utilisent la traite, au sens large du terme, soit à des fins de pilotage du système de production, soit à des fins de maîtrise de la qualité du lait. Il s'agit alors d'ajuster le niveau de production laitière (via les fréquences de traite), d'optimiser la quantité, la composition et la qualité microbiologique du lait collecté lors de la traite (via le matériel et les pratiques de traite), et de gérer la carrière et la santé des animaux ainsi que leurs courbes de lactation (via la fréquence de traite et la durée des lactations). Cette synthèse a pour but de présenter ces différents leviers et leurs effets, connus et moins connus.

\section{1 / La fréquence de traite, un outil d'ajustement du niveau de production laitière}

En France, depuis 1984, le régime des quotas laitiers implique une gestion annuelle de la production laitière sur les exploitations afin de mettre en cohérence le droit à produire des éleveurs et le lait livré aux laiteries. Cette régulation publique de l'offre sera relayée en 2015 par une régulation privée, sous forme de contrats passés avec les laiteries. Cette contractualisation incitera les éleveurs laitiers à ajuster leur production à l'échelle de l'année et selon des objectifs mensuels pour assurer la régularité des approvisionnements en lait de l'outil de transformation. La fréquence de traite des animaux est un des leviers qui permet de réduire ou d'augmenter rapidement la production de lait au niveau de l'exploitation.

\section{1 / Pour réduire la production de lait : la monotraite}

a) Des effets immédiats sur la production de lait qui s'accompagnent d'effets rémanents

La monotraite (1 seule traite/jour) se traduit par un allongement de la durée de l'intervalle entre traites. Cet allongement au delà de 16-18 h génère immédiatement des baisses de production laitière qui s'amplifient au cours de cet allongement : - 11 et $-21 \%$ respectivement pour des intervalles de 18 et $24 \mathrm{~h}$, comparés à un intervalle de $12 \mathrm{~h}$ (Stelwagen et al 2008). C'est pourquoi dans le cas de l'omission d'une traite hebdomadaire (suppression de la traite du dimanche soir), il est recommandé d'ajuster la durée des intervalles entre les traites adjacentes afin de limiter les pertes de lait, ces dernières restant alors modérées 
à l'échelle d'une lactation (- 1 à - 3,6\%, Meffe et al 2003).

La monotraite est peu pratiquée en France : seulement $1 \%$ des éleveurs laitiers adhérents au contrôle laitier la pratiquaient en Bretagne en 2006 (Michaud et al 2007). Le plus souvent, la monotraite est mise en œuvre durant 15 jours à 4 mois, essentiellement pour gérer le quota en fin de période hivernale et les fins de lactation lorsque les vêlages sont groupés (Huchon et al 2005, Michaud et al 2007), mais dans certaines exploitations c'est une composante à part entière du système de production : elle y est appliquée toute l'année.

La monotraite est un moyen rapide et efficace pour réduire la production de lait. Ses effets sont observés dès le $1^{\text {er }}$ jour et les niveaux de baisse moyens sont importants, de l'ordre de 20-30\% (Rémond et Pomiès 2005). En réduisant de façon drastique le volume de lait produit sur l'exploitation, la monotraite permet d'éviter $i$ ) la vente ou la réforme de vaches laitières en lactation et donc de décapitaliser et d'amputer le potentiel de production de l'exploitation, et ii) la réduction de l'apport de concentrés dont les effets peuvent être négatifs pour les animaux, notamment ceux à faible note d'état corporel.

La diminution de la fréquence de traite ou l'allongement de l'intervalle entre traites se traduit par des effets rémanents lors du retour à des intervalles réguliers. Ces effets ont été décrits dans le cas de l'omission d'une traite hebdomadaire (Pomiès et Rémond 2000, Meffe et al 2003) et d'une traite quotidienne (Rémond et Pomiès 2005). Ils diffèrent selon les modalités de mise en œuvre de cette conduite. Par exemple, il faut respectivement 24 et $48 \mathrm{~h}$ pour que le volume de lait redevienne normal après l'omission d'une seule traite ou l'omission d'une traite quotidienne pendant 1 à 3 semaines (Knight et Dewhurst 1994, Meffe et al 2003). En revanche, lorsque la monotraite est pratiquée durant plus de 3 semaines consécutives, ces effets rémanents perdurent et se traduisent par une perte de lait de l'ordre de $10 \%$. Cette perte est moindre lorsque la monotraite est appliquée tard dans la lactation (Rémond et Pomiès 2005).

b) Des réponses sur la production de lait très variables selon les animaux

Les résultats de la littérature décrivent des réponses à la monotraite qui varient fortement entre les lots suivant les essais : de - 19 à - 46\% de lait produit selon les lots et les facteurs étudiés (Pomiès et al 2008). Cette variabilité est aussi associée à une très grande hétérogénéité des réponses entre individus, hétérogénéité observée lors du passage en monotraite comme au retour à 2 traites/jour (Holmes et al 1992, Rémond et Pomiès 2005, Guinard-Flament et al 2011).

Plus les vaches produisent de lait, plus leur production (exprimée en $\mathrm{kg}$ ) diminue lors du passage en monotraite. Mais, pour un même niveau de production initiale, le niveau de réduction de la production laitière est très variable entre les individus : certaines vaches, plus sensibles, perdent $50 \%$ de leur production contre $10 \%$ pour les moins sensibles (Holmes et al 1992). De la même manière, la quantité de lait regagnée au retour à 2 traites/jour varie de façon non négligeable entre les individus, même si cette quantité est d'autant plus importante que la diminution de la production laitière était élevée lors du passage en monotraite (figure 1).

Cette hétérogénéité des réponses individuelles témoigne de la diversité des réponses adaptatives à la monotraite chez la vache laitière. Elle souligne l'enjeu de pouvoir identifier les individus les mieux adaptés, afin d'utiliser la monotraite comme outil de pilotage de la production de lait sur l'exploitation. Récemment, il a été montré que la description du potentiel adaptatif d'une vache laitière, indépendamment de son niveau de production, passe par l'analyse conjointe de 2 critères indépendants : la baisse de production laitière relative observée lors du passage en monotraite (exprimée en \%) et le taux de récupération au retour à 2 traites/jour (quantité de lait regagnée/quantité de lait perdue ; Guinard-Flament et al 2011). Parallèlement, des premiers phénotypes prédicteurs comme le Taux Butyreux (TB) du lait et le taux de lactose dans le plasma sanguin ont été identifiés (GuinardFlament et al 2011, Larroque et al 2011).

\section{2 / Pour accroître la produc- tion de lait : l'augmentation de la fréquence de traite}

La traite des vaches laitières 3 fois par jour en salle de traite est une pratique courante dans les régions où des exploitations de taille importante disposent d'une main-d'œuvre peu coûteuse par rapport au prix du lait (Californie, kibboutz d'Israël), notamment quand l'usage de l'hormone de croissance est autorisé (Etats-Unis). Mais elle reste marginale ailleurs dans le monde. Appliquée durant toute la lactation, cette pratique permet d'accroître la production de lait de 13 à $17 \%$ selon le niveau de complémentation des animaux par rapport à la traite biquotidienne (DePeters et al 1985), mais avec un surcoût non négligeable (temps de travail, aliments, produits de trempage et de lavage, électricité, usure du matériel). C'est pourquoi des études récentes tentent de cibler des périodes spécifiques de la lactation durant lesquelles le bénéfice d'un passage à 3 traites/jour serait maximum, en termes d'augmentation de production et d'effet rémanent sur la suite de la lactation. Certains auteurs ont en effet mis en évidence un arrière effet positif d'une fréquence de traite élevée en début de lactation, mais avec des risques pour la santé des animaux et à des rythmes difficilement applicables en élevage : 4 traites/jour durant les 3 premières semaines (Hale et al 2003) ou 6 traites/jour durant les 6 premières semaines (Bar-Peled et al 1995). Les essais portant sur 3 traites/jour en début de lactation ne mettent en évidence qu'un

Figure 1. Variations de production laitière observées lors du passage en monotraite (Perte de lait) et au retour à 2 traites/jour après 3 semaines de monotraite (Gain de lait) chez des vaches croisées Holstein x Normande (d'après Guinard-Flament et al 2011).

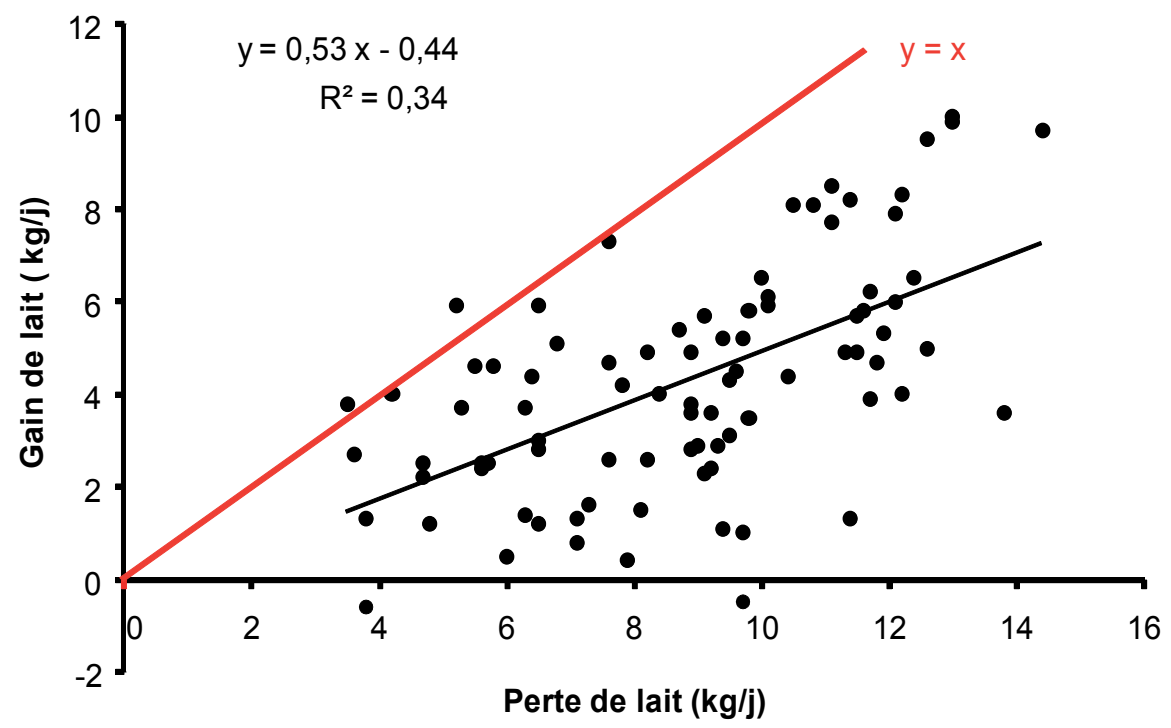


bénéfice transitoire sur le niveau de production, effet qui disparaît quelques semaines après le retour à 2 traites/jour (Andersen $e t$ al 2003, Norgaard et al 2005).

L'accroissement de la production laitière avec l'augmentation de la fréquence de traite reste néanmoins un concept intéressant en Europe, avec l'installation massive de robots de traite dans les élevages depuis une dizaine d'années. Ces machines pouvant traire les animaux plus de 3 fois par jour avec des troupeaux de taille adaptée à leur capacité, permettent en théorie une augmentation sensible des volumes de lait produits par vache. Dans la réalité cette augmentation est moins importante qu'attendue, en grande partie du fait d'une fréquence de traite moyenne moins élevée qu'attendue $(2,8$ à 2 fois par jour entre le début et la fin de lactation) et d'intervalles entre traites beaucoup plus irréguliers qu'en salle de traite (Pomiès et Lefeuvre 2001).

\section{3 / Les conséquences de la varia- tion de la fréquence de traite sur la composition du lait}

a) La composition générale : taux butyreux, taux protéique et taux de lactose

La composition du lait évolue en réponse aux variations de fréquence de traite sous l'effet de mécanismes différents selon les composés du lait. Le taux de lactose du lait diminue lors du passage en monotraite (jusqu'à - $5 \mathrm{~g} / \mathrm{kg}$ selon les essais, d'après Delamaire 2006) en réponse à une modification de la perméabilité de l'épithélium mammaire (Stelwagen et al 1997). Le TB du lait varie, quant à lui, de façon inverse à l'évolution de la production de lait (figure 2). Cette évolution du TB n'est pas due uniquement aux variations de volume de lait produit car la monotraite provoque aussi une diminution de la production de matières grasses, mais généralement moins importante que celle observée sur le volume de lait. Il en résulte globalement une augmentation du TB qui peut être importante $(+6 \mathrm{~g} / \mathrm{kg})$, alors que le passage à 3 traites/jour provoque des variations d'amplitude plus modérée.

Les variations du Taux Protéique (TP) du lait ne sont pas ou très faiblement corrélées aux variations de production laitière (figure 2). Ces variations peuvent atteindre jusqu'à $+3 \mathrm{~g} / \mathrm{kg}$ lors la monotraite mais sont d'amplitude plus faible chez des animaux traits 3 fois/ jour. Dans le cas de la monotraite, l'augmentation du TP s'expliquerait par un afflux de protéines solubles provenant du sang et par une diminution moindre de la synthèse protéique mammaire que du volume de lait. Cet effet sur la synthèse des protéines laitières pourrait trou- ver son origine dans l'amélioration du bilan énergétique des animaux (Rémond et Pomiès 2005).

Concernant les effets rémanents au retour à 2 traites/jour, Bar-Peled et al (1995) et Andersen et al (2003) n'ont pas observé de modifications de la composition du lait lorsque la fréquence de traite précédemment appliquée était de 6 et 3 traites/jour, respectivement. A contrario, Hale et al (2003) ont observé une diminution du TB et du TP durant les 6 semaines suivant le retour à 2 traites/ jour de vaches traites 4 fois par jour pendant leurs 3 premières semaines de lactation. Dans le cas de la monotraite, les taux reviennent rapidement à leur niveau initial, excepté le TP qui peut rester plus élevé (voire continuer à augmen-

ter) en réponse à l'amélioration du statut nutritionnel des animaux (Rémond et al 1999, Pomiès et al 2007, GuinardFlament et al 2011).

b) La composition fine du lait et l'aptitude à la transformation

\section{La matière protéique du lait}

L'augmentation du taux protéique en réponse à la diminution de la fréquence de traite est d'autant plus intéressante que la fraction caséinique n'est pas affectée négativement : soit elle augmente (Lacy-Hulbert et al 1999, Rémond et al 2004), soit elle reste stable (Auldist et Prosser 1998, O’Brien et al 2002). Cependant, la diminution de la fréquence de traite provoque une diminution du rapport

Figure 2. Variations du TB et TP en fonction des variations de production laitière lors de modifications du rythme de traite (variations rapportées aux valeurs mesurées à 2 traites/jour, d'après Delamaire 2006).

$$
+3 \text { traites/jour } \square 3 \text { traites en } 2 \text { jours } \Delta 1 \text { traite/jour }
$$

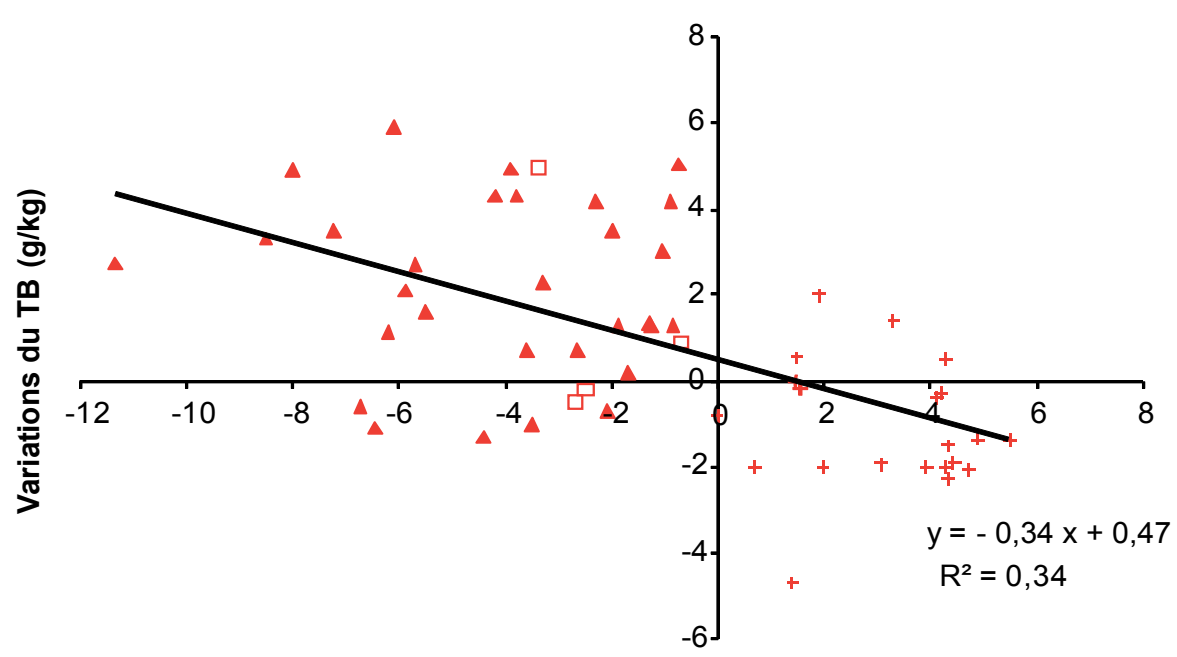

Variations de la production laitière (kg/jour)

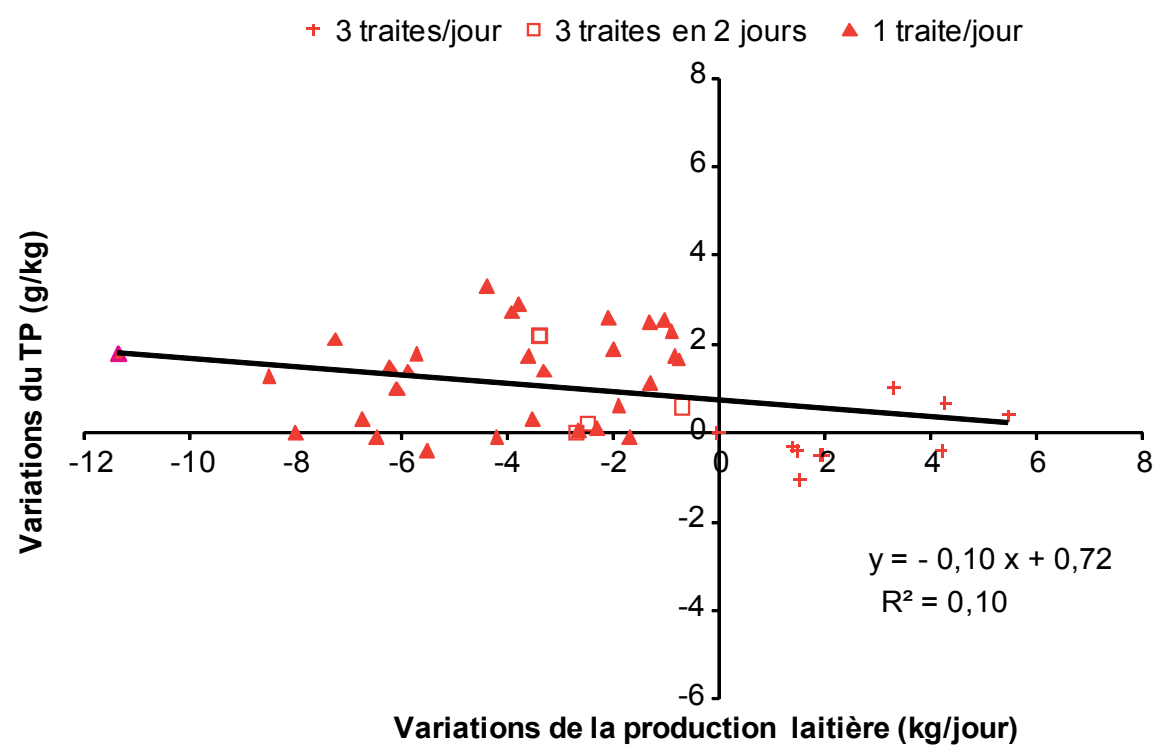


caséines/protéines (O’Brien et al 2002, Martin et al 2009) ou non (Rémond et al 2004), en raison de l'augmentation du taux de protéines du lactosérum. De même, le passage de 2 à 3 traites/jour provoque une diminution du taux des protéines solubles (albumine sérique, lactoferrine et immunoglobines $G$; Sorensen et al 2001).

La diminution de la fréquence de traite s'accompagne aussi d'une augmentation de l'activité protéolytique dans le lait, en raison de l'activation du complexe plasmine/plasminogène (Kelly et al 1998, Sorensen et al 2001, O'Brien et al 2002, Rémond et al 2004). Cette activation conduirait à accroître l'hydrolyse de la caséine $\beta$ en caséine $\gamma$ (de 2 à 1 traite/ jour : Prosser et al 1995, Lacy-Hulbert et al 1999, de 3 à 2 traites/jour : Sorensen et al 2001) mais pas de façon systématique : O'Brien et al (2002) n'ont pas noté de modifications des pourcentages des caséines $\alpha \mathrm{s} 1, \alpha \mathrm{s} 2, \beta, \kappa$ et $\gamma$ en réponse à la monotraite.

Ces changements pourraient modifier l'aptitude du lait à la transformation fromagère. Selon Martin et al (2009), la fabrication de fromage à pâte pressée non cuite est peu sensible aux modifications liées à monotraite, ce qui pourrait ne pas être le cas pour les fromages à pâte pressée cuite sensibles à la plasmine. En effet, si la monotraite augmente le temps de coagulation (O'Brien et al 2002, Martin et al 2009) et la vitesse de raffermissement (Martin et al 2009) sans effet sur la fermeté (Martin et al 2009) ou avec une fermeté des gels améliorée (O'Brien et al 2002), elle n'a pas d'effet significatif sur l'acidification, les cinétiques de drainage des fromages et le rendement fromager (Martin et al 2009). Cette absence d'effet de la monotraite, malgré une augmentation de la quantité de matières utiles dans le lait, est une conséquence de la diminution du ratio caséines/protéines entraînant une moindre récupération de caséines dans le caillé et une perte accrue de protéines solubles dans le lactosérum. De même, les effets de la monotraite sur les propriétés chimiques et sensorielles des fromages de type Cantal sont faibles (Martin et al 2009). Les fromages sont légèrement plus jaunes à cause d'une teneur plus élevée en béta-carotène dans les laits due à un effet de concentration (Nozière et al 2006). Les autres propriétés sensorielles ne sont pas modifiées, exceptée l'odeur de poivre qui est réduite.

\section{La matière grasse du lait}

Concernant la composition de la matière grasse, Delamaire et GuinardFlament (2006) n'ont pas observé de changements du profil en acides gras des laits en réponse à des variations croissantes (3 traites/jour) ou décrois- santes ( 3 traites en 2 jours et 1 traite/ jour) du rythme de traite. En revanche, selon Wiking et al (2006), la proportion d'acides gras polyinsaturés est plus faible dans le lait de 4 traites/jour comparé à un lait de 2 traites/jour. Le lait de monotraite contient aussi moins d'acides gras libres (Martin et al 2009) en raison probablement d'une diminution de l'activité de la lipoprotéine lipase, même si cette diminution n'a pas toujours été mise en évidence (Rémond et al 2004). A l'inverse, la teneur en acides gras libres est plus élevée dans le lait de 4 traites/jour (Klei et al 1997, Slaghuis et al 2004, Wiking et al 2006). Ce phénomène serait lié à une fragilité plus grande de la membrane des globules gras.

La monotraite ne modifie pas la structure physique de la matière grasse, en particulier le diamètre des globules gras (Couvreur et Hurtaud 2007). A l'inverse, lorsque la fréquence de traite augmente au-delà de 2 traites/jour, les globules gras sont de plus gros diamètres (Wiking et al 2006) : la production de globules gras de petite taille reste constante mais le nombre de globules gras de diamètres moyens ou gros augmente. Ainsi, si le taux horaire de synthèse du lait est plus élevé, la production de matériel membranaire est suffisante pour couvrir les globules gras nouvellement formés (Wiking et al 2006). Cette augmentation de la taille des globules gras est susceptible d'entraîner une diminution du temps de barattage des crèmes et de générer des beurres plus tartinables (Couvreur et Hurtaud 2007).

\section{Les minéraux du lait}

Il existe très peu de données sur l'impact de la fréquence de traite sur la teneur en minéraux majeurs du lait. Les résultats obtenus avec la monotraite montrent une absence d'effets (Rémond et al 2004) ou une faible augmentation de la teneur en phosphore (de 5 à 7\%, Pomiès et al 2007, Martin et al 2009).

\section{2 / Le matériel et les pra- tiques de traite, un levier pour optimiser la quantité, la composition et la qualité microbiologique du lait}

La traite est une étape sensible pour laquelle de nombreux conseils et recommandations en matière de pratiques et d'usage du matériel ont été élaborés. Cette caractéristique a même conduit au développement de méthodes de contrôle pour vérifier la conformité et le fonctionnement des installations de traite lors de leur mise en route et chaque année par la suite (respectivement, Certitraite ${ }^{\circledR}$
2007 et Optitraite ${ }^{\circledR}$ 2010). La machine à traire avec ses réglages, ses effets mécaniques et son nettoyage, ainsi que les techniques de préparation et de désinfection des trayons sont une source de variation de la qualité chimique, structurelle et microbiologique du lait. Le matériel doit être choisi et réglé au mieux afin de ne pas nuire à la santé de la mamelle et de prévenir l'apparition de défauts sur le lait (ou de les minimiser) tout en cherchant à optimiser la quantité de lait collecté. Conjointement, les pratiques d'hygiène influent sur la richesse du lait en germes et notamment les germes d'intérêt pour la transformation laitière.

\section{1 / L'effet des réglages de la machine à traire sur l'animal}

\section{a) Les paramètres de la pulsation}

La pulsation est définie par 2 critères : i) la fréquence de pulsation qui décrit le nombre de cycles de pulsation par minute, ces derniers consistant à réaliser alternativement une phase de succion et une phase de massage de la mamelle et, ii) le rapport de pulsation qui décrit les durées relatives des phases de succion et de massage par cycle de pulsation.

Le cycle de pulsation permet d'extraire le lait tout en massant la mamelle, ce qui évite la congestion du trayon (Clough et Dodd 1956) et a pour principal effet de stimuler le réflexe d'éjection du lait (décharge d'ocytocine), ainsi que la libération d'autres hormones à effet galactopoïétique comme la prolactine ou le cortisol (Marnet et al 1996). Ainsi, la traite via la fréquence de pulsation est un élément essentiel de la stimulation physiologique des animaux et donc d'optimisation de la quantité de lait collecté à court terme (au moment de la traite) et à long terme sur la lactation (Lollivier et Marnet 2005).

Pour que la traite se déroule dans de bonnes conditions, il importe de ne pas annuler les effets positifs du cycle de pulsation, notamment par l'utilisation de matériel inapproprié (manchon mal monté ou inadapté au gobelet, manchon trop rigide ou trop souple, diamètre de l'embouchure du manchon trop grand, lèvres de manchon trop dures...) ou par la perturbation de la routine de traite et de l'environnement (Bruckmaier et Wellnitz 2008).

La fréquence de pulsation résulte d'un compromis entre rapidité de traite et état sanitaire de la mamelle et il convient de la régler correctement. En France, la fréquence de pulsation est comprise entre 60 et 65 cycles/min et la norme NF ISO 5707 spécifie qu'elle doit rester dans 
une plage de variation de $+5 \%$ des préconisations du fabricant (Institut de l'élevage 2009). Des fréquences inférieures à 60 pulsations/min augmentent la durée de la traite alors que des fréquences supérieures à 75 pulsations/min, plus agressives pour le trayon, augmentent le risque d'infections (Institut de l'élevage 2009).

Quant au rapport de pulsation, son augmentation par l'accroissement du temps de succion sur le temps de massage a un effet proche d'un niveau de vide plus élevé. Si cela est efficace pour accélérer la traite, un rapport trop haut (plus de $66 \%$ ) pourra avoir des effets négatifs tant sur la mamelle que sur la qualité du lait collecté comme décrit ci-après (Mein 1992).

b) Le niveau de vide de la machine à traire

Le niveau de vide utilisé dans les machines à traire sert autant à faire tenir le faisceau trayeur sur la mamelle qu'à récupérer le lait éjecté par l'animal et le faire circuler dans l'installation. Les effets du niveau de vide dépendent donc $\mathrm{du}$ poids du faisceau trayeur et seront ressentis différemment selon que l'animal est sain ou atteint de mammites et selon la morphologie de sa mamelle.

Les niveaux de vide moyens recommandés sont en général compris entre 38 et $50 \mathrm{kPa}$ suivant que l'installation de traite est en ligne basse ou haute respectivement. En effet, si le niveau de vide est trop bas pour un faisceau donné, outre un ralentissement de la traite, il y a un risque croissant de glissement voire de chute des gobelets. Ce phénomène de glissement s'accompagne souvent de bruits de succion en salle de traite qui témoignent d'entrées d'air brutales au niveau du manchon. Ces entrées d'air entraînent à leur tour des fluctuations brutales et acycliques du vide sous le trayon, qui peuvent être responsables de projections de lait sur et même parfois dans les trayons adjacents. Ces projections de lait constituent le facteur majeur de transmission de germes d'un quartier à l'autre ou d'une vache à l'autre si le faisceau est contaminé. Il explique beaucoup de cas de mammites et d'élévation des comptages de cellules somatiques (CCS) du lait (Thiel et al 1973).

A l'inverse, un niveau de vide plus élevé accélèrera la traite, les effets dépendant du poids des gobelets trayeurs. Mais si le niveau de vide est trop haut pour un faisceau donné, les manchons peuvent grimper le long du trayon, notamment en fin de traite quand la mamelle se déforme plus facilement (Wattiaux 2013). L'extrémité du trayon se congestionne alors beaucoup plus.
Le sphincter du trayon peut s'hyperkératiniser et dans des cas extrêmes s'éverser entraînant des problèmes de nettoyage et de perte d'étanchéité du sphincter vis-à-vis des invasions bactériennes (Hamann 1990). La surtraite qui consiste à laisser le faisceau en place alors que le débit de lait est faible voire nul accroît ce risque, d'où l'intérêt de l'emploi de systèmes de décrochage automatique (Rasmussen 2004). Enfin, le « grimpage » du manchon peut resserrer la base du trayon au point d'empêcher l'écoulement du lait et provoquer la rétention de lait dans la mamelle (lait dit d'égouttage) et avoir des effets négatifs. Laisser en moyenne $0,55 \mathrm{~kg}$ de lait d'égouttage par demi-mamelle par jour systématiquement à chaque traite, suffit à diminuer la production de lait de $6-10 \%$ sur toute une lactation (Ebendorff et al 1987, Hamann et Dodd 1992). Ce lait retenu peut aussi accroître la multiplication bactérienne jusqu'à la traite suivante et donc le risque de mammites (O'Shea 1987).

Il est donc important de bien régler le niveau de vide de la machine à traire. Un niveau de vide faible de l'ordre de $36 \mathrm{kPa}$ ou moins ne se justifie pas dans le cas d'un troupeau sain, avec peu de mammites cliniques, des CCS faibles (100 000 à 150000 cellules $/ \mathrm{mL}$ par exemple) et des trayons normaux, car il peut ralentir sensiblement l'écoulement du lait dans l'installation et donc allonger la durée de la traite. Dans le cas d'un troupeau ayant des problèmes sanitaires associés à un mauvais état des trayons (éversions de sphincters, anneaux de compression, microhémorragies), il est possible de baisser le niveau de vide à moins de $38 \mathrm{kPa}$, car cela améliore significativement l'état de congestion des trayons (sous réserve d'un faisceau léger et d'une bonne tenue de celui-ci). Dans ce cas, le rapport de pulsation peut être augmenté afin de compenser, tout au moins en partie, l'augmentation non négligeable des temps de traite individuels des vaches (Billon et al 2004). Cependant, si la lipolyse du lait recueilli semble tout à fait satisfaisante et se situe toujours au-dessous du seuil de pénalité $(0,89 \mathrm{meq} / 100 \mathrm{~g}$ de matière grasse $)$, elle peut augmenter avec des rapports de pulsation élevés $(>66 \%)$ ce qui doit inciter à la prudence.

\section{2 / Les effets mécaniques de la machine à traire et du système de stockage du lait}

Les effets mécaniques affectent principalement l'intégrité de la matière grasse du lait. Selon Rasmussen et al (2006), les défauts les plus fréquemment rencontrés dans les troupeaux ayant un fort taux d'acides gras libres proviennent de problèmes liés à l'agitation (79\%), au pompage $(67 \%)$ et au refroidissement du lait (58\%). Ils imposent un contrôle régulier de l'installation de traite et de refroidissement du lait.

\section{a) Le brassage du lait}

Pour chasser le lait vers le lactoduc, les gobelets trayeurs doivent être équipés d'une entrée d'air au plus près de la base des trayons. De très petits orifices permettant des entrées d'air de 4 à 12 $\mathrm{L} / \mathrm{min}$ sont donc généralement présents sur les faisceaux trayeurs à la base des gobelets ou sur la griffe.

Si cette entrée d'air est réduite ou obstruée, la traite est ralentie car le lait stagne dans la griffe. Ce lait qui encombre la griffe empêche le vide d'atteindre les trayons provoquant des fluctuations de vide importantes dont les effets délétères ont été décrits plus hauts. Cet engorgement du faisceau peut aussi entraîner une remontée du lait jusqu'au trayon et contaminer ce dernier par des bactéries récupérées dans le faisceau provenant d'animaux traits précédemment.

A l'inverse, une entrée d'air anormalement élevée peut entraîner un brassage important du lait et modifier sa qualité. Plusieurs causes peuvent être à l'origine de ce problème : des trous recalibrés à force de débouchage avec des outils inadaptés, des fuites au niveau des raccords du lactoduc, des clapets de fermeture du vide des griffes, des vannes, des robinets à lait et des clapets anti-retour des pompes à lait, ou l'utilisation de manchons usagés ou mal adaptés à l'animal. Ainsi, une entrée d'air à la griffe de 20 $\mathrm{L} / \mathrm{min}$ (hors norme) augmente la lipolyse de $0,43 \mathrm{meq} / 100 \mathrm{~g}$ de matière grasse par rapport à une entrée d'air de 4 - $5 \mathrm{~L} / \mathrm{min}$ (niveau bas de la fourchette autorisée par la norme NF ISO 5707) (Institut de l'élevage 2009). Le passage du débit de l'air dans la griffe de 6 à seulement $13 \mathrm{~L} / \mathrm{min}$ augmenterait déjà significativement le taux d'acides gras libres (O'Brien et al 1998, Evers et Palfreyman 2001).

Une autre source de brassage du lait provient du transfert du lait vers le tank lorsque la hauteur de chute lors du déversement du lait dans le tank est trop importante (Diaz et al 2004). Il est possible de limiter ce risque en versant le lait tangentiellement aux parois de la cuve ou en forçant le remplissage par la bonde d'évacuation située en bas de la cuve (Institut de l'élevage 2009).

\section{b) Le pompage du lait}

Le lait arrive en fin de lactoduc dans une chambre de réception. Lorsque cette dernière est remplie à un certain niveau, une sonde permet d'activer la pompe de 
reprise qui va vider l'unité en transférant le lait vers le tank. Un pompage continuel du lait, de même que la vitesse de rotation des pompes de reprise, accroissent la lipolyse induite (Escobar et Bradley 1990, O’Brien et al 1998). Les laits à fort taux de matière grasse et à gros globules gras sont plus sujets à la coalescence et à la lipolyse lors du pompage que le lait issu d'animaux nourris avec des faibles apports de matière grasse ou avec des apports d'acides gras insaturés (Wiking et al 2005). Enfin, un pompage à $31^{\circ} \mathrm{C}$ au lieu de $4^{\circ} \mathrm{C}$ accrô̂t significativement la lipolyse d'où l'intérêt d'utiliser un pré-refroidisseur avant la reprise du lait vers le tank.

Lorsque le système de déclenchement des pompes à lait fonctionne mal (mauvais réglage ou présence de mousse), la pompe vide totalement l'unité terminale et finit par aspirer un mélange d'air et de lait qui provoque des turbulences et du moussage. L'accroissement de lipolyse observé peut alors être 3 à 4 fois supérieur à celui observé avec le même matériel bien réglé (Institut de l'élevage 2009).

\section{c) Le refroidissement du lait}

Le stockage et le refroidissement du lait sont souvent considérés, à tort, comme indépendants de la traite mécanique et de la conduite de traite des animaux alors qu'ils doivent être adaptés au nombre d'animaux et à leur production, au rythme de collecte par la laiterie mais aussi à la fréquence de traite des animaux et au système de traite utilisé. En particulier, les systèmes robotisés sont systématiquement vendus avec un dispositif de stockage/ réfrigération qui leur est spécifique.

Sous l'action de la réfrigération, il se produit une cristallisation fractionnée de la matière grasse accompagnée d'une rétraction du globule, ce qui altère la membrane et libère la graisse liquide. Outre un écrémage accéléré, cette altération favorise l'action des lipases dont l'activité est encore notable au voisinage de $0^{\circ} \mathrm{C}$. Cependant, le stockage dans le tank à basse température dans de bonnes conditions (bon fonctionnement du groupe frigorifique, capacité de la cuve adaptée aux quantités de lait à refroidir, démarrage du refroidissement une fois les pales des agitateurs recouvertes, baisse de la température jusqu'à $4{ }^{\circ} \mathrm{C}$ en moins de 2 h...) n'affecte pas la lipolyse (Jellema 1986) et les caractéristiques des globules gras, au moins jusqu'à $48 \mathrm{~h}$ de stockage (Couvreur et al 2005).

On peut cependant enregistrer des fluctuations de températures à chaque arrivée de lait qui n'excèdent jamais $15^{\circ} \mathrm{C}$, mais qui peuvent influencer significativement le taux d'acides gras libres
(Cartier et Chilliard 1989). L'usage d'un système de pré-refroidissement, comme les tanks tampons ou les pré-refroidisseurs à plaques ou tubulaires, pourra aussi limiter les variations de température dans le tank de stockage et le développement des germes lipolytiques (Hartman et al 2008). Les systèmes robotisés les proposent de plus en plus pour limiter la lipolyse due à l'arrivée continue de petits volumes de lait qui entraînent des remontées de température à chaque vache traite. L'arrivée de petits volumes dans un grand tank classique aux capacités de refroidissement élevées entraîne aussi un risque de gel du lait qui est plus problématique car la membrane des globules peut être cassée par les cristaux de matière grasse. Il faut donc choisir l'usage d'un tank à puissance limitée ou à double paroi (tank à eau glacée) ou encore utiliser un petit tank tampon de 300 litres avant le tank principal. Cela permet de limiter la puissance frigorifique du tank (et sa consommation énergétique) et donc les risques de gel et de lipolyse associée (Wiking et Nielsen 2007). Cet effet a surtout été mis en évidence dans des exploitations où les autres facteurs de risques de lipolyse sont importants et lorsque les niveaux de lipolyse sont élevés au préa- lable. Dans les autres situations, l'incidence est limitée.

\section{3 / La traite, un maillon pour la diversité microbienne du lait}

a) La gestion " amont 》 des communautés microbiennes des laits

Les communautés microbiennes du lait cru jouent un rôle prépondérant dans l'établissement des caractéristiques organoleptiques des fromages dont la richesse et la diversité dépendent des activités des populations microbiennes du lait cru, très diverses et en interaction les unes avec les autres (Bérodier et Spinnler 2011).

Le lait cru se caractérise par une grande diversité de microorganismes généralement classés en groupes, genres, espèces et souches. Les groupes microbiens les plus représentés sont les bactéries lactiques, les bactéries dites d'affinage (microcoques et corynébactéries), les bactéries propioniques, les bactéries à Gram négatif, les levures et les moisissures (tableau 1). Les récents inventaires de la diversité microbienne des laits crus de vache mettent en évidence au moins une quarantaine de genres microbiens différents, avec près de 150

Tableau 1. Inventaire non exhaustif et ordre de grandeur (UFC/mL) de quelques groupes microbiens couramment dénombrés dans les laits crus de vache (d'après Desmasures et al 1997, Michel et al 2001, Saubusse et al 2007, Mallet et al 2010, Vacheyrou et al 2011).

\begin{tabular}{|c|c|c|}
\hline Groupes microbiens & Genres & UFC/mL \\
\hline Bactéries lactiques & $\begin{array}{l}\text { Aerococcus } \\
\text { Enterococcus } \\
\text { Lactobacillus } \\
\text { Lactococcus } \\
\text { Leuconostoc } \\
\text { Streptococcus }\end{array}$ & $\begin{array}{l}100-1000 \\
10-100 \\
10-100 \\
10-100 \\
10-100\end{array}$ \\
\hline $\begin{array}{l}\text { Staphylocoques et } \\
\text { bactéries corynéformes }\end{array}$ & $\begin{array}{l}\text { Arthrobacter, Clavibacter, } \\
\text { Corynebacterium, Deinococcus, } \\
\text { Dermacoccus, Kocuria, } \\
\text { Macrococcus, Microbacterium, } \\
\text { Leucobacter, Leifsonia, Rothia, } \\
\text { Renibacterium, Staphylococcus }\end{array}$ & $100-1000$ \\
\hline Bactéries Gram négatif & $\begin{array}{l}\text { Acinetobacter, Brevundimonas, } \\
\text { Chryseobacterium, Comamonas, } \\
\text { Enterobacter, Hafnia, Klebsellia, } \\
\text { Ochrobactrum, Pseudomonas, } \\
\text { Psychrobacter, Serratia, } \\
\text { Shingobacterium, } \\
\text { Stenotrophomonas, Xanthomonas, } \\
\text { Yersinia }\end{array}$ & $100-1000$ \\
\hline Levures & $\begin{array}{l}\text { Candida, Cryptococcus, } \\
\text { Geotrichum, Issatchenkia, } \\
\text { Kazachstania, Kluyveromyces, } \\
\text { Pichia, Rhodotorula, Trichoderma, } \\
\text { Trichosporon }\end{array}$ & $10-100$ \\
\hline Moisissures & & $<10$ \\
\hline
\end{tabular}


Figure 3. La qualité microbienne du lait résulte d'un continuum d'écosystèmes microbiens.

\section{Communautés microbiennes des environnements}

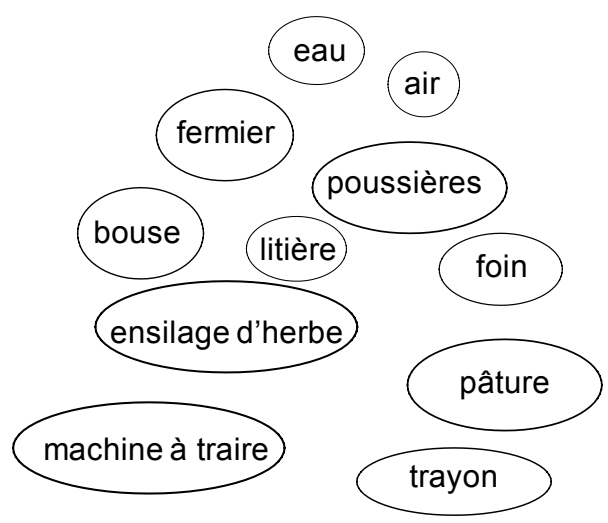

\section{Communauté microbienne du lait}

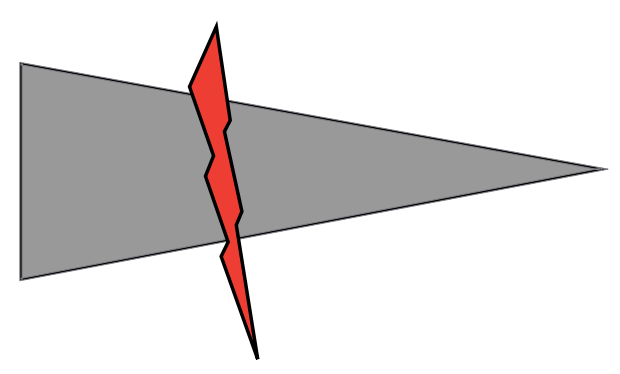

Points de rupture

- Pratiques de traite (lavage, essuyage, trempage des trayons)

- Machine à traire

- Refroidissement (conservation à $4^{\circ} \mathrm{C}$ )

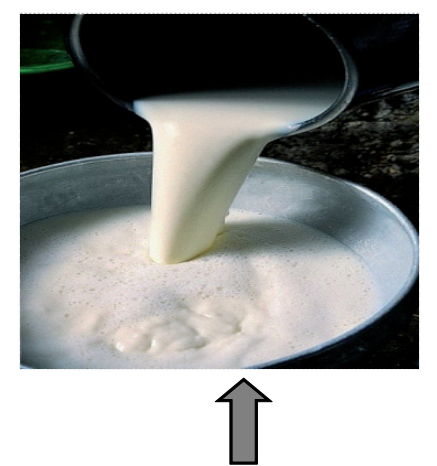

Ferments lactiques

Présure espèces différentes (Mallet et al 2010). Cette diversité devient exponentielle car les espèces se déclinent en plusieurs souches. Les microorganismes du lait cru peuvent également être classés selon leur rôle fonctionnel dans l'écosystème (lait, fromage...) : par exemple, les bactéries lactiques souvent abondantes dans le lait assurent la fonction d'acidification essentielle pour la transformation des produits laitiers. D'autres espèces, bien que présentes en plus petit nombre, peuvent pourtant jouer un rôle primordial dans le fonctionnement de l'écosystème. Tout est question d'équilibre et la survie de la communauté microbienne ne tient qu'aux multiples et diverses interactions entre d'une part, les populations microbiennes de l'écosystème et d'autre part, les méthodes de traite et de nettoyage des installations.

L'instauration, dans les années 1970 , de la loi Godefroy sur le paiement du lait à la qualité visait à interdire la collecte des laits ayant plus de 100000 microorganismes et 400000 cellules $/ \mathrm{mL}$. Cette réglementation a été renforcée avec l'imposition de critères microbiologiques (tolérance de 100000 germes à $30^{\circ} \mathrm{C}$ par $\mathrm{mL}$ de lait produit, Directive 92/46/CEE). Les pratiques d'hygiène très drastiques mises en œuvre ont ainsi réduit les niveaux des populations microbiennes qui sont aujourd'hui souvent inférieurs à 5000 germes par millilitre de lait (Michel et al 2001). Ces laits qualifiés de « pauci-microbiens » seraient mal adaptés pour la transformation fromagère en lait cru pour des raisons encore mal définies. Ils auraient perdu en diversité microbienne, quantitativement et qualitativement; or la diversité microbienne engendre de la diversité sensorielle (Buchin et al 1998) et est un atout pour la biopréservation des fromages et en particulier pour faire barrière à Listeria monocytogenes (Millet et al 2006, Roth et al 2010).

\section{b) Les réservoirs environnementaux de microorganismes}

$\mathrm{Au}$ sortir de la mamelle d'animaux sains, le lait est quasiment stérile (Tolle 1980 ) et sa contamination en microorganismes extrêmement faible ne contribue pas à son ensemencement. La littérature relate souvent que les environnements des fermes sont des sources de contamination du lait par les microorganismes pathogènes ou indésirables (Oliver et al 2005). En revanche, peu d'études soulignent le rôle de ces environnements comme réservoirs de flore microbienne d'intérêt technologique. Les fourrages, le pâturage (Verdier-Metz et al 2012b), les litières, les bouses, l'air (Vacheyrou et al 2011), les ambiances des bâtiments, l'eau, le trayon (peau et ou canal) des animaux (Michel et al 2001, Verdier-Metz et al 2012a) et le système de traite sont autant de sources potentielles de microorganismes susceptibles d'inoculer le lait directement ou indirectement (figure 3). Bouton et al (2007) ont mis en évidence des souches identiques de lactobacilles dans le lait, sur la peau des trayons et au niveau des manchons de la machine à traire démontrant qu'il existe un transfert de souches microbiennes entre la machine à traire et le lait.

Michel et al (2006), Vacheyrou et al (2011) et Verdier-Metz et al (2012a) ont montré que le trayon des vaches laitières est un réservoir majeur de microorga- nismes pouvant jouer un rôle de vecteur entre les environnements et le lait. Ils ont mis en évidence que la surface des trayons sains (sans blessures) des vaches laitières avant toute préparation pour la traite présente une grande diversité de groupes microbiens. La flore d'intérêt technologique (bactéries acidifiantes, flore intervenant dans l'affinage des fromages) y est largement représentée tandis que les microorganismes indésirables d'altération sont présents à des niveaux 100 fois plus faibles. Des pratiques de traite jugées «d'hygiène peu sécuritaire » et respectant la flore de la mamelle (absence de lavage, absence d'essuyage des trayons, absence de préet/ou post-trempage des trayons) sont plutôt associées à des laits dont le niveau global de microorganismes est élevé (D'Amico et Donelly 2010) et dont la diversité microbienne est importante, particulièrement en microorganismes d'intérêt technologique (Michel et al 2001, Verdier-Metz et al 2009).

c) La machine à traire, un autre réservoir

La machine à traire est recouverte de biofilms (adhésion de microorganismes) à sa surface et constitue un réservoir potentiel de microorganismes pour le lait qui s'enrichit par le détachement partiel des biofilms. Mais les groupes microbiens de ces biofilms semblent peu diversifiés. En effet, Michel et al (2006) ont quantifié dans l'eau de rinçage de la machine à traire des populations microbiennes d'intérêt technologique appartenant aux groupes des bactéries lactiques (lactobacilles, lactocoques, entérocoques...) à des niveaux la plupart du temps identiques à ceux des populations 
dites « indésirables 》 (groupes microbiens pouvant être à l'origine d'altération ou potentiellement pathogènes). Mais les pratiques de nettoyage de la machine à traire tendent à modifier les équilibres microbiens dans le lait: une température de l'eau supérieure à $75^{\circ} \mathrm{C}$ ou un mauvais rinçage ont conduit à des faibles niveaux en bactéries lactiques et d'affinage dans les laits (Arnal 1999). De même, la fréquence de nettoyage et l'alternance acide/base conduiraient à des laits plus chargés en flore d'altération (bactéries coliformes et Pseudomonas) (Chatelin et Richard 1983, Michel et al 2005).

Les équilibres microbiens des laits résultent d'une combinaison de pratiques de production dont la hiérarchisation est encore difficile en raison d'une connaissance insuffisante des flux microbiens de l'environnement au lait. Cependant, l'entretien de la machine à traire, les pratiques de traite et l'hygiène de la peau des trayons des animaux semblent jouer un rôle primordial dans la composition microbienne des laits.

\section{3 / La traite, un outil de pilo- tage du système de produc- tion}

Au-delà de l'ajustement du niveau de production laitière et de l'optimisation de la composition et de la qualité du lait, la traite peut aussi servir à piloter certaines phases du cycle de production de tout ou partie des vaches du troupeau. Ce pilotage peut se faire de nouveau par la fréquence quotidienne de traite (augmentation ou diminution) pendant des périodes clés de la lactation, mais aussi en modulant la durée de la lactation elle-même (ou a contrario la durée du tarissement).

\section{1 / Pour gérer l'état nutrition- nel, la reproduction et les patho- logies du troupeau}

a) La monotraite en début de lactation pour améliorer la reproduction en contrôlant la phase de mobilisation des réserves corporelles

Malgré les pertes de lait qu'elle entraîne, la monotraite est parfois employée dès le vêlage, pendant des durées de l'ordre de 3 à 6 semaines. Durant cette période, l'ingestion des animaux en monotraite reste identique à celle de vaches traites 2 fois par jour (Rémond et al 1999, 2002 et 2004) tandis que leur production laitière est réduite de 20 à $34 \%$. Il en résulte une plus faible mobilisation des réserves corporelles (Rémond et al 1999) et un meilleur bilan énergétique (Rémond et al 1999 et 2002). Cela permet une réduction sensible de la période d'anœstrus post-partum et parfois une amélioration des performances de reproduction (Rémond et al 2004, Clark et al 2006). Cette pratique est ainsi mise en œuvre par des éleveurs qui souhaitent que toutes leurs vaches se reproduisent sur une période très courte afin de grouper les vêlages et de pouvoir fermer la salle de traite durant 2 mois.

b) La monotraite en fin de lactation pour favoriser la reconstitution des réserves corporelles ou éviter de la pénaliser lorsque la ressource fourragère est limitée

A l'opposé de la pratique précédente, certains éleveurs choisissent d'appliquer la monotraite en fin de lactation, que ce soit pour des raisons économiques (réduction du personnel de traite), pour faciliter le tarissement (Tucker et al 2009) ou pour permettre aux vaches de reconstituer leurs réserves corporelles avant le vêlage suivant (seules les vaches les plus maigres d'un troupeau pouvant être concernées). Cette pratique, mise en œuvre en Nouvelle-Zélande les années où la ressource fourragère au pâturage limite fortement les performances laitières, permet aux vaches en monotraite de regagner entre 0,2 et 0,4 points de note d'état corporel en fin de lactation (sur une échelle de 1 à 10) alors que celles traites deux fois par jour ne commencent à en regagner qu'après le tarissement (Lee et Dalley 2009).

c) La monotraite contre les boiteries pour les animaux pâturant des parcelles éloignées

La monotraite est une pratique qui permet de réduire les distances parcourues quotidiennement par les vaches, comme en Nouvelle-Zélande où, avec l'augmentation de la taille des fermes, la distance moyenne actuelle entre les pâtures et la salle de traite est de $1,9 \mathrm{~km}$ (Tucker et al 2007). Elle peut également n'être mise en œuvre que sur des vaches atteintes de boiterie, qui ne sont ramenées en salle de traite qu'une fois par jour jusqu'à leur guérison (Reveley 2007).

Dans les systèmes laitiers herbagers de montagne, le ralentissement de la pousse de l'herbe durant l'été oblige les éleveurs à pâturer des parcelles de plus en plus éloignées, obligeant les animaux à parcourir quotidiennement des distances de plusieurs kilomètres et entraînant l'apparition de boiteries. Si la solution la plus classique pour pallier ce problème est de pâturer des parcelles éloignées le jour et des parcelles proches la nuit, il est également possible pour l'éleveur de passer l'ensemble du troupeau en monotraite; bien que non étudiée en tant que telle, la perte financière engendrée par le lait « non produit » est vraisemblablement minime. En effet, dans ce type de systèmes où les vêlages sont généralement groupés à l'automne, la monotraite intervient en fin de lactation, là où son impact sur la production laitière est le plus faible (Pomiès et al 2004). Cette perte financière est à mettre en parallèle avec les principales conséquences engendrées par les boiteries : frais vétérinaires, diminution importante de production laitière liée à la baisse d'ingestion (Bareille et al 2003), temps consacré aux soins, risque de réforme prématurée, etc.

d) L'augmentation de la fréquence de traite pour traiter les mammites sans antibiotiques

La traite au moins 4 fois par jour d'un quartier de la mamelle présentant des signes de mammite clinique est une pratique souvent en vigueur chez les éleveurs qui souhaitent réduire le nombre de traitements antibiotiques, notamment en agriculture biologique. Cela favoriserait l'élimination des agents pathogènes, des toxines et des médiateurs inflammatoires contenus dans le lait du quartier infecté (Eberhart et al 1987). Cependant, les études les plus récentes (Krömker et al 2010) ne permettent pas de confirmer l'intérêt de cette pratique, certaines données suggérant même qu'elle peut être préjudiciable à l'animal avec certains types de germes (Roberson et al 2004).

A l'inverse, de nombreux auteurs ont décrits l'impact de la monotraite sur la santé de la mamelle. Si pour de courtes périodes il est avéré que la monotraite n'entraine qu'une augmentation rapide et limitée à 4-5 jours des CCS (Stelwagen et Lacy-Hulbert 1996, Rémond et Pomiès 2007), les conséquences à long terme de cette pratique posent plus de problèmes. En effet, plus la durée de monotraite s'accroît, plus on observe une augmentation des CCS (Rémond et al 2004, Lacy-Hulbert et al 2005), notamment chez les vaches ou les troupeaux ayant déjà des valeurs élevées, jusqu'à atteindre des niveaux pouvant pénaliser le paiement du lait aux éleveurs. Cette augmentation des CCS semble due à une réaction inflammatoire bénigne entraînant un afflux de leucocytes polynucléaires neutrophiles dans le lait (Stelwagen et Lacy-Hulbert 1996). Elle n'apparaît pas associée à une augmentation du nombre de mammites cliniques (Rémond et al 2004, Lacy-Hulbert et al 2005). Cependant, des données recueillies sur plusieurs générations de primipares au cours de leurs 18 premières semaines de lactation (en bâtiment), montrent un nombre d'animaux atteints de mammites cliniques significativement supérieur chez celles conduites en monotraite (27 contre $10 \%$; Pomiès et Rémond, non publié). 


\section{2 / Pour gérer la courbe de lac- tation}

\section{a) La persistance de la lactation}

Si l'augmentation de la fréquence de traite quotidienne de 2 à 3 permet une augmentation rapide de la production laitière comme nous l'avons vu précédemment (cf. § 1.2), son utilisation pendant plusieurs semaines consécutives (voire pendant toute la lactation) permet également d'augmenter la persistance laitière, calculée comme la pente de la courbe de lactation au-delà du pic de lactation (Sorensen et al 2008, BernierDodier et al 2010). Cela peut être mis à profit pour allonger la durée classique de lactation (voir ci-dessous). Cependant, pour être économiquement rentable, ce système semble plutôt réservé aux élevages équipés de robots de traite en « sous-capacité », pour lesquels l'augmentation de la fréquence de traite est possible et ne nécessite pas de main d'œuvre supplémentaire. A l'inverse, pour Rémond et al (2004), la réduction de la fréquence de traite quotidienne de 2 à 1 ne modifie pas la persistance de lactation hebdomadaire après le pic de vaches multipares alimentées de façon identique $(98,2$ vs $98,1 \%)$, bien que, pour Hickson et al (2006), elle la réduise significativement pour des troupeaux comprenant $20 \%$ de primipares, mais avec un chargement au pâturage supérieur de $17 \%$ pour les animaux en monotraite.

\section{b) L'allongement de la lactation}

Dans les races bovines laitières, la lactation dure généralement 10 mois. Cependant, en l'absence de gestation, il est possible de produire du lait plus longtemps grâce au maintien de la traite biquotidienne, dont l'effet galactopoïétique entretient la lactation. Des études récentes ou en cours tentent d'évaluer l'intérêt de lactations prolongées au-delà de 305 jours, notamment pour pallier les problèmes de reproduction, avec des intervalles vêlage-vêlage (IVV) de 14 à 18 , voire 24 mois, subis ou programmés.

En France, une étude de Trou et al (2010) a montré que $20 \%$ des lactations ont une durée supérieure à 395 jours. Sur 90000 lactations « longues » étudiées (441 jours en moyenne avec une production de $19 \mathrm{~kg} / \mathrm{j}$ à 305 jours), $79 \%$ étaient subies par les éleveurs suite à des problèmes de reproduction (fécondations tardives) et $21 \%$ étaient volontairement allongées (mise à la reproduction tardive).

A l'étranger aussi (Suède, Danemark, Grande-Bretagne, Australie, NouvelleZélande...) les problèmes liés à l'augmentation du niveau de production laitière (production encore élevée au tarissement, troubles métaboliques après vêlage, difficultés de reproduction, santé de la mamelle...) incitent éleveurs et chercheurs à tester d'autres modèles de production économiquement viables, plus respectueux du bien-être des vaches et basés sur des lactations plus longues (Auldist et al 2007, Sorensen et al 2008). Dans les élevages où le groupement des vêlages n'est pas une obligation, l'allongement de la lactation, peut être programmé pour décaler la période de reproduction de certaines vaches au-delà du pic de lactation, à une période où elles ne sont plus en bilan énergétique négatif. Par ailleurs, $65 \%$ des incidents de santé se produisant dans les 45 premiers jours de lactation, le remplacement de trois cycles production de 12 mois par deux de 18 mois réduirait les risques d'un tiers. Dans certains pays comme l'Australie ce système permettrait en outre aux éleveurs de bénéficier d'un prix du lait plus attractif en hiver et d'une meilleure répartition de leur trésorerie au cours de l'année (Grainger et al 2009). Des essais récents (Kolver et al 2007) montrent que même pour des systèmes entièrement à l'herbe comme en Nouvelle-Zélande, des lactations longues (en l'occurrence de 20 à 22 mois) pourraient avoir un intérêt économique, notamment en combinant certains types génétiques avec un apport minimum de concentré. La baisse de production laitière est en grande partie compensée par l'augmentation de la matière utile (base de paiement du lait en NouvelleZélande), les notes d'état en période de reproduction sont améliorées $(+1,7$ points en moyenne sur une échelle de 1 à 10 ) et le pourcentage de vaches non gestantes réduit $(16,5$ vs $31 \%)$. De tels systèmes permettraient de diminuer les coûts « additionnels » par vache (reproduction, vêlage, santé...), de réduire les périodes de fragilité des animaux et donc d'augmenter leur longévité et de diviser par deux le nombre de génisses de renouvellement. Pour conserver une utilisation régulière du pâturage, ces systèmes seraient possibles en faisant vêler la moitié du troupeau chaque année afin de synchroniser les débuts de lactation avec la courbe de production de l'herbe.

\section{c) La durée de la période de tarisse- ment}

Même avec un IVV d'environ 12 mois, il est possible d'augmenter la durée de lactation en réduisant (voire supprimant) la période de tarissement, ou Période «Sèche » $(\mathrm{PS})$. Les résultats présentés ici proviennent en grande partie d'une synthèse très récente que Rémond (2010) a consacrée à cette pratique. La durée classique de PS chez la vache laitière est de 60 jours; de très nombreuses études ont montré que cette durée est nécessaire pour faciliter le renouvellement cellulaire dans la glande mammaire et qu'elle permet de maximiser la production laitière cumulée des lactations $n$ et $n+1$, notamment chez les primipares dont la mamelle ne serait pas encore entièrement développée. Mais chez les multipares hautes productrices dont le début de lactation est de plus en plus souvent associé à une incidence accrue de maladies métaboliques et de troubles de la reproduction, la réduction de la durée de la PS à 30-40 jours deviendrait envisageable (Collier et al 2012). Elle entraîne systématiquement une diminution de la production laitière lors de la lactation suivante, de 5 à $10 \%$ pour une PS de 30 jours à $20 \%$ pour une PS inférieure à 10 jours, avec une courbe de lactation classique mais au pic moins élevé. Les modifications de composition du lait observées en fin de lactation s'amplifient en fin de gestation : forte augmentation du taux butyreux et de la lipolyse, du taux protéique (proportionnellement plus pour les protéines solubles que pour les caséines) et des CCS ; diminution du taux de lactose. Le début de lactation suivante se traduit généralement par un taux protéique et des CCS plus élevés.

Si avec des PS d'environ 60 jours il est classique de mettre les animaux à la diète au tarissement puis de réintroduire progressivement une alimentation riche au cours des 3 dernières semaines de gestation (pour permettre aux microorganismes du rumen de s'adapter au régime hautement énergétique qui suit le vêlage), avec des PS réduites il devient possible de ne pas modifier l'alimentation des animaux. Cela entraîne moins de stress et, après vêlage, un accroissement plus rapide de la capacité d'ingestion, moins de pertes de poids vif et d'état corporel, un meilleur bilan énergétique et des paramètres métaboliques sanguins améliorés. Ainsi, les résultats d'essais (Schlamberger et al 2010) ou des observations de terrain montrent effectivement que la réduction de la durée de la PS est souvent associée à une baisse des incidents métaboliques (fièvre vitulaire, cétose...), mais du fait de leur faible fréquence d'apparition cette corrélation ne peut être mise en évidence statistiquement. Il en va de même pour l'amélioration des performances de reproduction (en liaison avec le meilleur bilan énergétique) qui nécessiterait d'être confirmée avec des effectifs de vaches plus importants. En revanche, la hausse des CCS et l'incidence des mammites liées à la réduction de la PS peuvent représenter un vrai danger : d'une part, la période de tarissement est favorable aux infections mammaires et sa suppression serait une alternative intéressante; d'autre part, cette période est souvent l'occasion de réaliser des traitements antibiotiques 
pour assainir certains quartiers de la mamelle et débuter une nouvelle lactation avec de faibles niveaux de CCS.

\section{Conclusion}

En France, la modulation des fréquences de traite est surtout utilisée pour répondre à des attentes sur la gestion du travail. Cet article montre que ces pratiques et toutes celles liées au réglage de la machine à traire et au déroulement de la traite n'ont pas ce seul intérêt, mais permettent de répondre à des besoins très variés allant de l'ajustement du niveau de production laitière de l'exploitation à l'optimisation de la qualité du lait pour son paiement, en passant par la gestion de la lactation, de la carrière et de la santé des animaux. Ainsi la traite est un outil à part entière de pilotage du système de production et de maîtrise de la qualité du lait en élevage laitier, au même titre que l'alimentation et la génétique.

Néanmoins, ces pratiques ne sont pas sans effets secondaires multiples qui peuvent être bénéfiques ou négatifs ou associés à des arrières-effets notables capables de perdurer dans le temps. Aussi, pour que la traite devienne un outil pertinent de pilotage de la production laitière, de maîtrise de la qualité du lait ou de gestion du troupeau, il importe d'intégrer l'ensemble de ces réponses afin de trouver le juste compromis et piloter au mieux le système biotechnique.
Le développement de nouvelles technologies autour du matériel de traite avec les possibilités de déploiement de biocapteurs laissent entrevoir la possibilité de raisonner la traite au sens large du terme, non plus à l'échelle du troupeau mais à l'échelle de l'individu. Parce que ces biocapteurs permettront de mesurer les traits physico-chimiques du lait ou les traits morphologiques de la mamelle en lien avec la qualité du lait, l'état corporel de l'animal, la santé de l'animal et de la mamelle, ils permettront d'identifier au plus vite des pratiques inadéquates ou des dysfonctionnements de matériels, mais aussi de cibler les animaux les mieux adaptés aux modulations de la conduite de traite choisies par l'éleveur.

\section{Références}

Agabriel J., Farrie J.P., Pottier E., Note P., Pomiès D., 2012. Conséquences zootechniques de simplifications de pratiques : exemples de la distribution des aliments et de la traite des vaches. In : Travail en élevage. Hostiou N., Dedieu B., Baumont R. (Eds). INRA Prod. Anim., 25, 141-158.

Andersen J.B., Friggens N.C., Sejrsen K., Sorensen M.T., Munksgaard L., Ingvartsen K.L., 2003. The effects of low vs high concentrate level in the diet on performance in cows milked two or three times daily in early lactation. Livest. Prod. Sci., 81, 119-128.

Arnal A., 1999. Influence des pratiques d'élevage et des conditions de production sur la flore utile du lait. Rapport de stage ENITAC, 80 p.

Auldist M.J., Prosser C.G., 1998. Differential effects of short-term once-daily milking on milk yield, milk composition and concentrations of selected blood metabolites in cows with low or high pasture intake. Proc. N.Z. Soc. Anim. Prod., 58, 41-43.

Auldist M.J., O'Brien G., Cole D., Macmillan K.L., Grainger C., 2007. Effects of varying lactation length on milk production capacity of cows in pasture-based dairying systems. J. Dairy Sci., 90, 3234-3241.

Bar-Peled U., Maltz E., Bruckental I., Folman Y., Kali Y., Gacitua H., Lehrer A.R., Knight C.H., Robinzon B., Voet H., 1995. Relationship between frequent milking or suckling in early lactation and milk production of high producing dairy cows. J. Dairy Sci., 78, 2726-2736.

Bareille N., Beaudeau F., Billon S., Robert A., Faverdin P., 2003. Effects of health disorders on feed intake and milk production in dairy cows. Livest. Prod. Sci., 83, 53-62.

Bernier-Dodier P., Delbecchi L., Wagner G.F., Talbot B.G., Lacasse P., 2010. Effect of milking frequency on lactation persistency and mammary gland remodeling in mid-lactation cows. J. Dairy Sci., 93, 555-564.

Bérodier A., Spinnler H.E., 2011. Microflore du lait et caractéristiques sensorielles des fromages. In : Réseau Fromages de Terroirs : Microflore du lait cru - vers une meilleure connaissance des écosystèmes microbiens du lait et de leurs facteurs de variation, ouvrage collectif coordonné par Cécile Laithier (Ed). RMT Fromages de Terrroirs, 130p., 29-39.

Billon P., Gaudin V., Marnet P.G., 2004. Effects of very low-working vacuum levels on milking and udder health of dairy cows. In: 100 years with liners and pulsators in machine milking, Bruges, Belgium. Bull. Int. Dairy Fed., 388, 91.

Bouton Y., Guyot P., Vacheyrou M Normand A.C., Piarroux R., Beuvier E., 2007. Etude des flux bactériens dans les étables de production laitière de Franche-Comté. Exemple des Lactobacilles hétérofermentaires facultatifs. $15^{\text {eme }}$ Colloque du Club des Bactéries Lactiques, 13-15 novembre, Rennes, France.

Bruckmaier R., Wellnitz O., 2008. Induction of milk ejection and milk removal in different production systems. J. Anim. Sci., 86, 15-20.

Buchin S., Delague V., Duboz G., Berdague J.L., Beuvier E., Pochet S., Grappin R., 1998. Influence of pasteurization and fat composition of milk on the volatile compounds and flavor characteristics of a semi-hard cheese. J. Dairy Sci., 81, 3097-3108.

Cartier P., Chilliard Y., 1989. Lipase redistribution in cow's milk during induced lipolysis. I. Activation by agitation, temperature change, blood serum and heparin. J. Dairy Res., 56, 699-709.

Certitraite ${ }^{\circledR}, 2007$. Référentiel : règles de montage et performances pour les installations de traite mécanique. COFIT Institut de l'Elevage, 40p.

Chatelin Y.M., Richard J., 1983. Comparaison, dans des conditions courantes, de l'efficacité de quatre méthodes de nettoyage des machines à traire. Lait, 63, 87-101.

Chauvat S., Seegers J., N'Guyen The B., Clément B., 2003. Le travail d'astreinte en élevage bovin laitier. Synthèse nationale d'enquêtes "Bilan Travail". In : Institut de l'Elevage (Ed), 1-50.

Clark D.A., Phyn C.V., Tong M.J., Collis S.J., Dalley D.E., 2006. A systems comparison of once-versus twice-daily milking of pastured dairy cows. J. Dairy Sci., 89, 1854-1862.

Clough P.A., Dodd F.H., 1956. Effect of pulsation rate and ratio on milking rate. Agriculture, London, U.K., 63, 334-335.

Collier R.J., Annen-Dawson E.L., Pezeshki A., 2012. Effects of continuous lactation and short dry periods on mammary function and animal health. Animal, 6, 403-414.

Couvreur S., Hurtaud C., 2007. Le globule gras du lait : sécrétion, composition, fonctions et facteurs de variation. INRA Prod. Anim., 20, 365-382.

Couvreur S., Hurtaud C., Peyraud J.L., 2005. Effet du système de traite et du stockage du lait en tank sur la taille des globules gras. Renc. Rech. Rum., 12, 412.

D’Amico D.J., Donnelly C.W., 2010 Microbial quality of raw milk used for smallscale artisan cheese production in Vermont: effect of farm characteristics and practices. J. Dairy Sci., 93, 137-147.

Delamaire E., 2006. Régulation du prélèvement et de l'utilisation des nutriments par la glande mammaire en réponse à une diminution de la fréquence de traite chez la vache laitière. Thèse de doctorat de l'Ecole Nationale Supérieure d'Agronomie de Rennes, France, 177p.

Delamaire E., Guinard-Flament J., 2006. Longer milking intervals alter mammary epithelial permeability and the udder's ability to extract nutrients. J. Dairy Sci., 89, 2007 2016.

DePeters E.J., Smith N.E., Acedo-Rico J., 1985. Three or two times daily milking of older cows and first lactation cows for entire lactations. J. Dairy Sci., 68, 123-132.

Desmasures N., Bazin F., Gueguen M., 1997. Microbiological composition of raw milk from selected farms in the Camembert region of Normandy. J. Appl. Microbiol., 83, 53-58.

Diaz J. R., Peris C., Rodriguez M., Molina M. P., Fernandez N., 2004. Effect of milking pipeline height on machine milking efficiency 
and milk quality in sheep. J. Dairy Sci., 87 , 1675-1683.

Ebendorff W., Kram K., Michel G., Ziesack J., 1987. Machine stripping, milk yield and udder health - results over 4 lactations. Milchwissenschaft, 42, 23-25.

Eberhart R.J., Harmon R.J., Jasper D.E., Natzke R.P., Nickerson S.C., Reneau J.K., Row E.H., Smith K.L., Spencer S.B., 1987. Current concepts of bovine mastitis. The National Mastitis Council, Arlington, Virginia, 47p.

Escobar G.J., Bradley Jr R.L., 1990. Effect of mechanical treatment on the free fatty acid content of raw milk. J. Dairy Sci., 73, 20542060.

Evers J.M., Palfreyman K.R., 2001. Free fatty acid levels in New-Zealand raw milk. Aus. J. Dairy Tech., 56, 198-201.

Grainger C., Auldist M.J., O'Brien G., Macmillan K.L., Culley C., 2009. Effect of type of diet and energy intake on milk production of Holstein-Friesian cows with extended lactations. J. Dairy Sci., 92, 1479-1492.

Guinard-Flament J., Gallard Y., Larroque H., 2011. Lactose in blood plasma and the ability of dairy cows to tolerate once-daily milking in terms of milk loss and milk recovery. J. Dairy Sci., 94, 3446-3454.

Hale S.A., Capuco A.V., Erdman R.A., 2003. Milk yield and mammary growth effects due to increased milking frequency during early lactation. J. Dairy Sci., 86, 2061-2071.

Hamann J., 1990. Effects of machine milking on teat end condition with special emphasis on infection risk. World Rev. Anim. Prod., 25 17-24.

Hamann J., Dodd F.H., 1992. Milking Routines. In: Machine Milking and Lactation, Bramley A.J., Dodd F.H., Mein G.A., Bramley J.A. (Eds). Insight Books, England, 79-80.

Hartmann W., Reis F.R., Masson M.L., 2008. Plates' pre-cooling enhances preservation of raw milk on farm level: a way to improve Brazilian milk quality. Ars Veterinaria, Jaboticabal, SP, 24, 110-116.

Hickson R.E., Lopez-Villalobos N., Dalley D.E., Clark D.A., Holmes C.W., 2006. Yields and persistency of lactation in Friesian and Jersey cows milked once daily. J. Dairy Sci., 89, 2017-2024.

Holmes C.W., Wilson G.F., Mackenzie D.D.S., Purchas J., 1992. The effects of milking once daily throughout lactation on the performance of dairy cows grazing on pasture. Proc. N.Z. Soc. Anim. Prod., 52, 13-16.

Huchon J.C., Goulard L., Désarménien D., Sabatté N., Gaboriau L., Rubin B., 2005. A la recherche de solutions pour améliorer les conditions de travail en élevage laitier. Passage à une traite par jour sur une période de 1 à 2 mois. Fiche $\mathrm{N}^{\circ} 2$. Institut de l'Elevage, Chambres d'Agriculture Pays de Loire (Eds), 1-4.

Institut de l'élevage, 2009. Traite des vaches laitières - Matériel, installation, entretien. Collection Produire mieux. France Agricole Editions, France, 555p.

Jellema A., 1986. Some factors affecting the susceptibility of raw cow milk to lipolysis. Milchwissenschaft, 41, 553-557.

Kelly A.L., Reid S., Joyce P., Meaney W.J., Foley J., 1998. Effect of decreased milking frequency of cows in late lactation on milk somatic cell count, polymorphonuclear leucocyte numbers, composition and proteolytic activity. J. Dairy Res., 65, 365-373.

Klei L.R., Lynch J.M., Barbano D.M., Oltenacu P.A., Lednor A.J., Bandler D.K., 1997. Influence of milking three times a day on milk quality. J. Dairy Sci., 80, 427-436.

Knight C.H., Dewhurst R.J., 1994. Once daily milking of dairy cows: relationship between yield loss and cisternal milk storage. J. Dairy Res., 61, 441-449.

Kolver E.S., Roche J.R., Burke C.R., Kay J.K., Aspin P.W., 2007. Extending lactation in pasture-based dairy cows: I. Genotype and diet effect on milk and reproduction. J. Dairy Sci., 90, 5518-5530.

Krömker V., Zinke C., Paduch J.H., Klocke D., Reimann A., Eller G., 2010. Evaluation of increased milking frequency as an additional treatment for cows with clinical mastitis. J. Dairy Res., 77, 90-94.

Lacy-Hulbert S.J., Woolford M.W., Nicholas G.D., Prosser C.G., Stelwagen K., 1999. Effect of milking frequency and pasture intake on milk yield and composition of late lactation cows. J. Dairy Sci., 82, 1232-1239.

Lacy-Hulbert S.J., Dalley D.E., Clark D.A., 2005. The effects of once a day milking on mastitis and somatic cell count. Proc. N.Z. Soc. Anim. Prod., 65, 137-142.

Larroque H., Guinard-Flament J., Barbey S., Robert-Granie C., Pomiès D., Gallard Y., 2011. Premiers phénotypes de la tolérance à la monotraite chez les vaches laitières. Renc. Rech. Rum., 18, 352.

Lee S., Dalley D.E., 2009. Once a day milking: A practical option for summer dry conditions. http://www.dairynz.co.nz/file/fileid/33266

Lollivier V., Marnet P.G., 2005. Galactopoetic effect of milking in lactating holstein cows: Role of physiological doses of oxytocin. Livest. Prod. Sci., 95, 131-142.

Mallet A., Guéguen M., Desmasures N., 2010. Etat des lieux de la diversité microbienne quantitative et qualitative de laits crus normands destinés à la transformation fromagère. $8^{\text {ème }}$ Cong. Nat. Soc. Fr. Microbiol., 2-4 juin, Marseille, France.

Marnet P.G., Combaud J.F., Le Du J., Dano Y., 1996. Effects of pulsation rate and vacuum level on oxytocin release, milk parameters and teat end reaction. In: Proc. Symp. on Milk Synthesis, Secretion and Removal in Ruminants, Berne, Switzerland, April 26-27, 114.

Martin B., Pomies D., Pradel P., VerdierMetz I., Remond B., 2009. Yield and sensory properties of cheese made with milk from Holstein or Montbeliarde cows milked twice or once daily. J. Dairy Sci., 92, 4730-4737.

Meffe N., Tache C., Gaudin V., Marnet P.G., 2003. Suppression d'une traite par semaine pendant toute la lactation chez les vaches laitières à haut potentiel : effets zootechniques et caractéristiques physico-chimiques du lait. Renc. Rech. Rum., 10, 85-88.

Mein G.A., 1992. Action of the cluster during milking. In: Bramley A.J., Dodd F.H., Mein G.A., Bramley J.A. (Eds). Machine milking and lactation. Insight Books, Berkshire, U.K., 97-140.

Michaud A., Peyrin M., Massiot A., Berville A., Guinard-Flament J., Portier B., Brocard V., 2007. Quelle utilisation de la monotraite dans les élevages bovins laitiers en Bretagne? Renc. Rech. Rum., 14, 423.

Michel V., Hauwuy A., Chamba J.F., 2001. La flore microbienne des laits crus de vache : diversité et influence des conditions de production. Lait, 81, 575-592.

Michel V., Hauwuy A., Montel M.C., Coulon J.B., Chamba J.F., 2005. Pratiques d'élevage et composition microbienne des laits crus. Symp. Int. Territoires et Enjeux du Développement Régional, 9-11 mars, Lyon, France.

Michel V., Hauwuy A., Chamba J.F., 2006. Gestion de la flore microbienne des laits crus par les pratiques des producteurs. Renc. Rech. Rum., 13, 309-312.

Millet L., Saubusse M., Didenne R., Tessier L., Montel M.C., 2006. Control of Listeria monocytogenes in raw-milk cheeses. Int. J. Food Microbiol., 108, 1, 105-114.

Norgaard J., Sorensen A., Sorensen M.T., Andersen J.B., Sejrsen K., 2005. Mammary cell turnover and enzyme activity in dairy cows: effects of milking frequency and diet energy density. J. Dairy Sci., 88, 975-982.

Nozière P., Graulet B., Lucas A., Martin B., Grolier P., Doreau M., 2006. Carotenoids for ruminants: from forages to dairy products. Anim. Feed Sci. Technol., 131, 418-450.

O’Brien B., O’Callaghan E., Dillon P., 1998. Effect of various milking machine systems and components on free fatty acid levels in milk. J. Dairy Res., 65, 335-339.

O'Brien B., Ryan G., Meaney W.J., McDonagh D., Kelly A., 2002. Effect of frequency of milking on yield, composition and processing quality of milk 42. J. Dairy Res., 69, 367-374.

Oliver S.P., Jayarao B.M., Almeida R.A., 2005. Foodborne pathogens in milk and the dairy farm environment: food safety and public health implications. Foodborne Path. Dis., 2, 115-129.

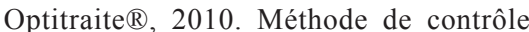
Optitraite ${ }^{\circledR}$ pour les installations de traite mécanique. COFIT Institut de l'Elevage, Etude du Département Techniques d'Elevage et Qualité (DTEQ) ISBN 2-84148-027-5, 64p.

O'Shea J., 1987. Machine milking factors affecting mastitis. In: Machine milking and mastitis, Brussels, Belgium. Bull. Int. Dairy Fed., 215, 5-32.

Pomiès D., Lefeuvre N., 2001. Impact réel d'un robot de traite sur la production laitière des vaches. Renc. Rech. Rum., 8, 263.

Pomiès D., Rémond B., 2000. Omission de une ou deux traites par semaine sur des vaches laitières en milieu de lactation. Renc. Rech. Rum., 7, 128.

Pomiès D., Rémond B., Pradel P., 2004. Performances des vaches laitières et qualité du lait lors de la monotraite et après retour à 2 traites par jour, en fonction de la durée de cette pratique et du stade de lactation des animaux. Renc. Rech. Rum., 11, 225-228.

Pomiès D., Martin B., Chilliard Y., Pradel P., Rémond B., 2007. Once-a-day milking of Holstein and Montbéliarde cows for 7 weeks in mid-lactation. Animal, 1, 1497-1505.

Pomiès D., Marnet P.G., Cournut S., Barillet F., Guinard-Flament J., Rémond B., 2008. Les conduites de traite simplifiées en élevage laitier : vers la levée de l'astreinte biquotidienne. In : Numéro spécial, 20 ans de recherches en 
productions animales à l'INRA. Charley B., Herpin P., Perez J.M. (Eds). INRA Prod. Anim., 21, 59-70.

Prosser C.G., Nicholas G., Stelwagen K., Lacy-Hulbert S.J., Woolford M.W., McFadden T.B., 1995. Influence of milking frequency and feeding level on plasmin activity and casein degradation in milk. Proc. N.-Z. Soc. Anim. Prod., 55, 9-11.

Rasmussen M.D., 2004. Overmilking and teat condition. In: Proc. Ann. Meet. Nat. Mastitis Council, 43, 169-175.

Rasmussen M.D., Wiking L., Bjerring M., Larsen H.C., 2006. The influence of air intake on the level of free fatty acids and vacuum fluctuations during automatic milking. J. Dairy Sci., 89, 4596-4605.

Rémond B., 2010. Effet de la durée de la période sèche sur les performances des vaches laitières. In : Journ. Nat. GTV Antibiothérapie : santé animale et santé publique. SNGTV, Lille, France, 1031-1040.

Rémond B., Pomiès D., 2005. Once-daily milking of dairy cows: a review of recent French experiments. Anim. Res., 54, 427-442.

Rémond B., Pomiès D., 2007. Once-daily milking of Holstein cows for one-week decreases milk yield by twenty-five percent without any carry-over effect. Livest. Sci., 110, 192-195.

Rémond B., Coulon J.B., Nicloux M., Levieux D., 1999. Effect of temporary oncedaily milking in early lactation on milk production and nutritional status of dairy cows. Ann. Zootech., 48, 341-352.

Rémond B., Aubailly S., Chilliard Y., Dupont D., Pomiès D., Petit M., 2002. Combined effects of once-daily milking and feeding level in the first three weeks of lactation on milk production and enzyme activities, and nutritional status, in Holstein cows. Anim. Res., 51, 101-117.

Rémond B., Pomiès D., Dupont D., Chilliard Y., 2004. Once-a-day milking of multiparous Holstein cows throughout the entire lactation: milk yield and composition, and nutritional status. Anim. Res., 53, 201-212.

Reverley G., 2007. Strategic use of once-aday (OAD) milking. Dexcel and LIC (Eds). 39-43.

Roberson J.R., Warnick L.D., Moore G., 2004. Mild to moderate clinical mastitis: Efficacy of intramammary amoxicillin, frequent milk-out, a combined intramammary amoxicillin, and frequent milk-out treatment versus no treatment. J. Dairy Sci., 87, 583-592.
Roth E., Miescher Schwenninger S., Hasler M., Eugster-Meier E., Lacroix C., 2010. Population dynamics of two antilisterial cheese surface consortia revealed by temporal temperature gradient gel electrophoresis. BMC Microbiol., 10:74.

Saubusse M., Millet L., Delbès C., Callon C., Montel M.C., 2007. Application of Single Strand Coformation Polymorphism-PCR method to differentiate the cheese bacterial communities inhibiting Listeria monocytogenes. Int. J. Food Microbiol., 116, 126-135.

Schlamberger G., Wiedemann S., Viturro E., Meyer H.H.D., Kaske M., 2010. Effects of continuous milking during the dry period or once daily milking in the first 4 weeks of lactation on metabolism and productivity of dairy cows. J. Dairy Sci., 93, 2471-2485.

Slaghuis B.A., Bos K., de Jong O., Tudos A.J., de Giffel M.C., de Koning C.J.A.M., 2004. Robotic milking and free fatty acids. In: A Better Understanding - Automatic Milking. Meijering A., Hogeveen H., de Koning C.J.A.M. (Eds). Wageningen Academic, Wageningen, The Netherlands, 341-347.

Sorensen A., Muir D.D., Knight C.H., 2001. Thrice-daily milking throughout lactation maintains epithelial integrity and thereby improves milk protein quality. J. Dairy Res., $68,15-25$.

Sorensen A., Muir D.D., Knight C.H., 2008. Extended lactation in dairy cows: effects of milking frequency, calving season and nutrition on lactation persistency and milk quality. J. Dairy Res., 75, 90-97.

Stelwagen K., Lacy-Hulbert S.J., 1996. Effect of milking frequency on milk somatic cell count characteristics and mammary secretory cell damage in cows. Am. J. Vet. Res., 57, 902-905.

Stelwagen K., Farr V.C., McFadden H.A., Prosser C.G., Davis S.R., 1997. Time course of milk accumulation-induced opening of mammary tight junctions, and blood clearance of milk components. Am. J. Physiol., 273, R379R386.

Stelwagen K., Farr V.C., Nicholas G.D., Davis S.R., Prosser C.G., 2008. Effect of milking interval on milk yield and quality and rate of recovery during subsequent frequent milking. Livest. Sci., 114, 176-180.

Thiel C.C., Cousins C.L., Westgarth D.R., Neave F.K., 1973. The influence of some physical characteristics of the milking machine on the rate of new mastitis infections. J. Dairy Res., 40, 117-129.
Tolle A., 1980. The microflora of the udder. In: Factors influencing the bacteriological quality of raw milk. Int. Dairy Fed. Bull., 120, 4.

Trou G., Piquemal B., Brocard V., Disenhaus C., Herisset R., Jouanne D., Le Guennic M., Portier B., 2010. Caractérisation de 90000 lactations "longues" de vaches de race Prim Holstein. Renc. Rech. Rum., 17, 166.

Tucker C.B., Dalley D.E., Burke J.L.K., Clark D.A., 2007. Milking cows once daily influences behavior and udder firmness at peak and mid lactation. J. Dairy Sci., 90, 1692-1703.

Tucker C.B., Lacy-Hulbert S.J., Webster J.R., 2009. Effect of milking frequency and feeding level before and after dry off on dairy cattle behavior and udder characteristics. J. Dairy Sci., 92, 3194-3203.

Vacheyrou M., Normand A.C., Guyot P., Cassagne C., Piarroux R., Bouton Y., 2011. Cultivable microbial communities in raw cow milk and potential transfers from stables of sixteen French farms. Int. J. Food Microbiol., 146, 253-262.

Verdier-Metz I., Michel V., Delbès C., Montel M.C., 2009. Do milking practices influence the bacterial diversity of raw milk? Food Microbiol., 26, 305-310.

Verdier-Metz I., Gagne G., Bornes S., Monsallier F., Veisseire P., Delbès-Paus C., Montel M.C., 2012a. Cow teat skin, a potential source of diverse microbial populations for cheese production. Appl. Env. Microbiol., 78, 326-333

Verdier-Metz I., Monsallier F., Montel M.C., 2012b. Place des pâturages des bovins laitiers dans les flux microbiens laitiers. Fourrages (à paraître).

Wattiaux M.A., 2013. Lactation and milking: Principles of milking. Dairy essentials, Chapter 21, 81-84 [Online], Available: http:// babcock.wisc.edu/node/206

Wiking L., Nielsen J.H., 2007. Effect of automatic milking systems on milk quality. J. Anim. Feed Sci., 16, Suppl. 1, 108-116.

Wiking L., Bertram H.C., Bjorck L., Nielsen J.H., 2005. Evaluation of cooling strategies for pumping of milk - Impact of fatty acid composition on free fatty acid levels. J. Dairy Res., 72, 476-481.

Wiking L., Nielsen J.H., Bavius A.K., Edvardsson A., Svennersten-Sjaunja K., 2006. Impact of milking frequencies on the level of free fatty acids in milk, fat globule size, and fatty acid composition. J. Dairy Sci., 89, 10041009.

\section{Résumé}

Cette synthèse fait le point sur les effets directs et les conséquences de modifications de la conduite des animaux à la traite. Les effets recherchés répondent à des besoins de pilotage du troupeau ou de maîtrise de la qualité du lait. Ils visent à ajuster le niveau de production laitière sur l'exploitation, optimiser la qualité chimique, structurelle et microbienne du lait et piloter la conduite du troupeau. Les moyens pour intervenir sont variés allant de modifications de fréquence/intervalles de traite, à l'optimisation de la conception et des réglages de la machine à traire et des systèmes de stockage/réfrigération du lait en passant par les pratiques de traite. Il ressort de cette synthèse que la modulation de la fréquence de traite est un outil efficace pour moduler la production de lait et la durée de la lactation, et qu'elle peut contribuer à améliorer les performances de reproduction, gérer les réserves corporelles des vaches et dans certains cas limiter l'apparition de boiteries. Les choix de matériel de traite et de stockage/refroidissement du lait ainsi que les réglages de la machine à traire permettent d'optimiser l'extraction du lait, la durée de la traite et de collecter et conserver un lait d'une qualité maîtrisée sans nuire à la santé de la mamelle. Enfin, l'entretien de la machine à traire, les pratiques de traite et la peau des trayons des animaux semblent jouer un rôle primordial sur la richesse des laits crus en germes d'intérêt pour l'industrie laitière, les équilibres microbiens résultant d'une combinaison de pratiques de production dont la hiérarchisation reste encore difficile. 


\begin{abstract}
Milking as a management tool on dairy farms

This review covers the effects of alterations to the standard milking routine in order to manage on-farm milk production, optimise the component and microbial composition of milk and optimise herd management, through altering milking frequency and milking intervals, proper functioning of the milking machine and hygiene practices during milking. It is discussed how milking frequency can be an effective tool to manage both milk production and lactation length, as well as to improve reproductive performance and body condition and to reduce the incidence of lameness in cows. The review also highlights the role of the milking machine in determing milking speed and milk quality. Finally it is discussed how the proper maintenance of the milking machine, the milking practice itself and the skin condition of the teats are critical factors in controlling the microbial profile in unpasteurized milk.
\end{abstract}

GUINARD-FLAMENT J., MARNET P.-G., VERDIER-METZ I., HURTAUD C., MONTEL M.-C., STELWAGEN K., POMIÈS D., 2013. La traite, un outil de pilotage du troupeau et de maîtrise de la qualité du lait en élevage bovin laitier. In : Numéro spécial, La vache et le lait. Faverdin P., Leroux C., Baumont R. (Eds). INRA Prod. Anim., 26, 2, 193-206. 